\title{
DOES THE PULMONARY AUTOGRAFT IN THE AORTIC POSITION IN ADULTS INCREASE IN DIAMETER? AN ECHOCARDIOGRAPHIC STUDY
}

Raymond B. Hokken, $\mathrm{MD}^{\mathrm{a}}$

Ad J. J. C. Bogers, MD, PhD

Meindert A. Taams, $\mathrm{MD}, \mathrm{PhD}^{\mathrm{b}}$

Mieke B. Schiks-Berghourt ${ }^{\mathrm{b}}$

Lex A. van Herwerden, $\mathrm{MD}, \mathrm{PhD}^{\mathrm{a}}$

Jos R. T. C. Roelandt, $\mathrm{MD}, \mathrm{PhD}^{\mathrm{b}}$

Egbert Bos, MD, PhD
Objective: The objective of this study was to discern the fate of the pulmonary autograft diameter over time in adults and its relation to aortic regurgitation in the setting of aortic root replacement. Methods: From January 1989 to May 1995, 36 consecutive adult patients underwent aortic root replacement with a pulmonary autograft for aortic valve disease. The mean age of 20 male and 16 female patients was 29.1 years (range 19.3 to 52.1 years). The mean follow-up was 2.3 years (range 0.3 to 6.0 years). Two patients died in the hospital. One other patient had a second operation for stenosis at the distal suture line of the allograft in the pulmonary position. Pulmonary autograft anulus and sinus diameters were measured with epicardial echocardiography before (only anulus) and after cardiopulmonary bypass, with transthoracic echocardiography at hospital discharge, and with transesophageal echocardiography during follow-up. Results: The mean autograft anulus diameter did not increase immediately after cardiopulmonary bypass (mean diameter $26.2 \mathrm{~mm}$ before and $26.4 \mathrm{~mm}$ after cardiopulmonary bypass). The mean autograft sinus diameter after cardiopulmonary bypass was $36.5 \mathrm{~mm}$. The mean autograft anulus diameter increased to $31.5 \mathrm{~mm}$ at follow-up, an increase of $5.1 \mathrm{~mm}(19 \%)$. The mean autograft sinus diameter increased to $43.9 \mathrm{~mm}$ at follow-up, an increase of $7.4 \mathrm{~mm}(20 \%)$. Fifty-nine percent of the anulus diameter increase and $40 \%$ of the sinus diameter increase was already reached at hospital discharge $(7$ to 10 days after the operation); the other part of the increase occurred during follow-up. Diameter increase was associated with neither the length of follow-up (follow-up less than 1 year compared with a longer follow-up) or severity of aortic regurgitation. Conclusion: Pulmonary autograft anulus and sinus diameters increase the first year after aortic root replacement with a pulmonary autograft. This occurs rapidly within 10 days after the operation, with a further increase during follow-up, without causing significant aortic regurgitation at medium-term follow-up. ( $J$ Thorac Cardiovasc Surg 1997;113:667-74)
$T^{\mathrm{h}}$ he pulmonary autograft procedure is a surgical technique for treatment of aortic valve or root disease. Although the initially reported series

From the Departments of Cardiopulmonary Surgery ${ }^{\mathrm{a}}$ and Cardiology ${ }^{\mathrm{b}}$ of the University Hospital Sophia-Dijkzigt, Rotterdam, The Netherlands.

Received for publication April 8, 1996; revisions requested June 20, 1996; revisions received Dec. 5, 1996; accepted for publication Dec. 9, 1996.

Address for reprints: Raymond B. Hokken, MD, Cardiopulmonary Surgery, BD 156, University Hospital Dijkzigt, Rotterdam, Dr. Molewaterplein 40, 3015 GD Rotterdam, The Netherlands.

Copyright (c) 1997 by Mosby-Year Book, Inc.

$0022-5223 / 97 \$ 5.00+0 \quad 12 / 1 / 79787$ mainly comprised children, the autograft is now more often used in older patients as well. ${ }^{1-4}$ The expected lifelong durability without degeneration and the absence of the need for anticoagulants offer considerable advantages for adult patients. In contrast to the subcoronary or intraaortic cylinder implantation techniques, the root replacement technique is advantageous because it is technically less demanding. 2,5 The autograft is exposed to higher pressures, which may result in an increase of its diameter. An increase in autograft diameter has been reported in children, being explained as growth. ${ }^{6-8}$ In adults an increase in diameter has not been reported so far. ${ }^{2,4}$ The purpose of this study is to present serial measurements of the pulmonary 
autograft anulus and sinus diameters and their relation to aortic regurgitation in an adult patient group.

\section{Patients and methods}

We initially performed the pulmonary autograft procedure in November 1988 in a child. However, children (age $<17$ years) were not incorporated in the present study. From January 1989 until May 1995, 36 consecutive adults ( 20 male and 16 female patients with a mean age of 28.7 years, ranging from 19.0 to 52.0 years) underwent aortic root replacement with a pulmonary autograft for aortic valve disease. The nature of the original aortic valve disease was congenital $(n=27)$, degenerative $(n=5)$, cured endocarditis $(n=3)$, or annuloaortic ectasia $(n=$ 1). The hemodynamic diagnosis was aortic stenosis in $\mathbf{1 3}$ patients, regurgitation in 16 , and both stenosis and regurgitation in seven patients. A discrete subaortic stenosis was present in two patients in addition to valvular stenosis. Standard procedures were applied with regard to cardiopulmonary bypass (CPB) techniques, using moderate hypothermia and crystalloid cardioplegic arrest. ${ }^{3}$ The autograft was placed on the left ventricular outflow tract and anulus with a short rim of right ventricular muscle. No attempts were made to wrap the autograft or to reinforce the base of the autograft. Extended Ross procedures were not used and annular enlargement was not performed. For replacement of the pulmonary root, a cryopreserved pulmonary allograft was used in 35 patients and an aortic allograft in one patient.

Echocardiography. Epicardial echocardiography was routinely used after sternotomy to evaluate aortic valve disease and pulmonary valve function at the onset of the procedure. The autograft and allograft function were studied immediately after CPB. Seven to 10 days after the operation a transthoracic echocardiogram was performed. After discharge, all patients visited the outpatient clinic at 3 and 6 months after the operation and yearly thereafter. Twenty-eight patients consented to transesophageal echocardiography during the past year (six patients refused). The interval between the operation and transesophageal echocardiography therefore varies according to the length of follow-up of each patient. All echocardiograms were made on a Toshiba echocardiographic machine (SSH 140, Toshiba Corp., Tokyo, Japan) and taped on VHS videotape. Multiplane transesophageal echocardiography was performed with a $5 \mathrm{MHz}$ probe (Oldelft Instruments, Delft, The Netherlands). Measurements were made offline with a two-dimensional contour acquisition program on a personal computer with electronic callipers.

Autograft diameters were measured at two different levels: the anulus at the level of the autograft leaflet hinges and the sinus of Valsalva at the largest anteroposterior diameter. This was done in the long-axis plane from a two-dimensional image (with the largest diameters of the proximal autograft visible) using the inner wall distance during systole, with maximal opening of the valve leaflets. At each level, five cardiac cycles with the best quality were used for measurements. At transesophageal echocardiography, aortic regurgitation was measured semiquantitatively. For interobserver variability, 25 diam- eter measurements (at discharge and at follow-up) were analyzed by a second observer. Aortic regurgitation was scored as none if there was no regurgitation jet, trivial if a short, narrow jet was present just beneath the aortic valve, mild if the jet was limited to the left ventricular outflow tract, moderate if a broad jet reached halfway across the ventricle, and severe if a broad jet reached more than halfway across the ventricle.

Statistical analysis. A correlation coefficient was calculated for the anulus diameters measured with epicardial echocardiography before and after the autograft procedure. A paired $t$ test was used for analysis of the difference of the diameter between two time points.

For graphic representation of the mean autograft anulus and sinus diameters at follow-up, a "moving band" method was used. ${ }^{9}$ This method was chosen because of the variable follow-up period. With this method the mean follow-up time and the mean diameter were calculated for the five patients with the shortest follow-up period. Then the "band" moved in time, incorporating the sixth patient and excluding the first patient. For these patients a mean follow-up period and a mean diameter were calculated again. This was repeated until the five patients with the longest follow-up period were included. The width of the "band" thus consisted of five patients and varied with time. So that the individual behavior of the autograft anulus and sinus diameters could be clarified, the diameter increase was shown for each patient with at least two measurements.

For comparison and the relative increase of pulmonary autograft anulus and sinus diameters after the operation, only patients with all measurements available were analyzed. For two patients without an epicardial echocardiogram after $\mathrm{CPB}$, the anulus measurements before $\mathrm{CPB}$ were used. A $t$ test with paired variables was used for the difference of the mean at different time points. Beside this test we performed a repeated-measurements analysis, with four measurements of the autograft anulus diameter and three measurements of the autograft sinus diameter. This analysis was performed with multivariate analysis of variance (MANOVA) in SPSS for Windows (SPSS, Inc., Chicago, III.).

The relation of the increase in autograft anulus and sinus diameter to the length of follow-up was tested with a $t$ test, dividing the patients into two groups: one group with a transesophageal echocardiogram less than 1 year after the operation and another group with a transesophageal echocardiogram longer than 1 year after the operation. The relation of the increase in autograft anulus and sinus diameter to the severity of aortic regurgitation was tested with a $t$ test, dividing the patients into two groups according to the semiquantitative measurement of aortic regurgitation (none and trivial versus mild and moderate).

The intratechnique variability consisted of the variability within one observer, using five different images for measurements. The standard deviation of these measurements was calculated. The mean of these standard deviations for each level at each time point was determined and regarded as characteristic for the intratechnique variability. The interobserver variability was determined by the mean difference between two observers and the standard 


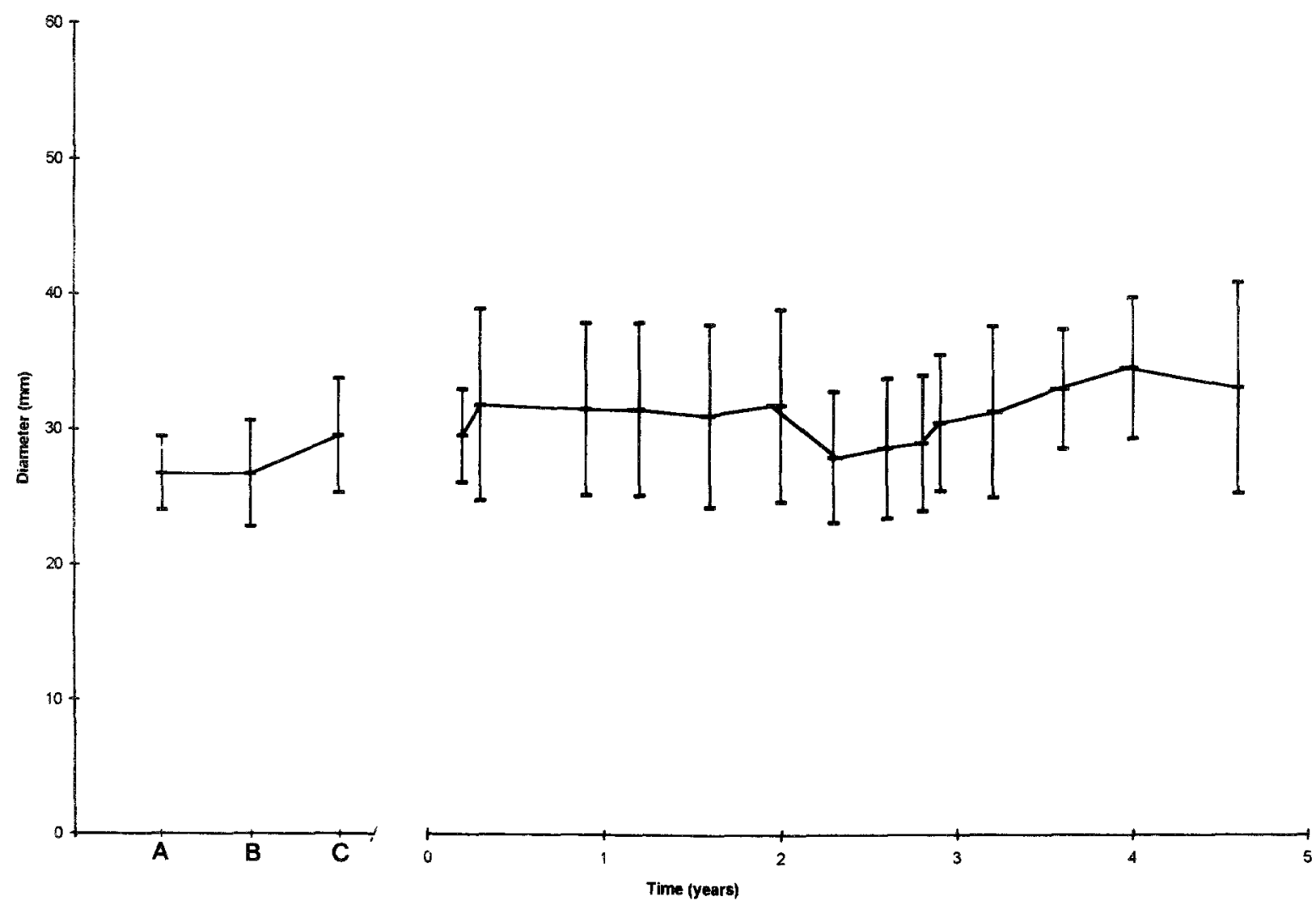

Fig. 1. Mean autograft anulus diameter, using all available measurements of 34 patients, before CPB $(A)$, after CPB $(B)$, at discharge $(C)$, and at follow-up. For the transesophageal echocardiographic measurements at follow-up, a "moving band" method was used. The mean anulus diameter is given with a $70 \%$ confidence interval.

deviation of this difference. Statistical significance for all analyses was assumed if the $p$ value was less than 0.05 .

\section{Results}

Patients. Two patients died in the hospital (5.6\%). One patient, preoperatively in cardiogenic shock, died 4 hours after the operation of a pulmonary embolus originating from the prostatic plexus. The other patient died 2 weeks after the operation of low output; this patient had required a second operation for aortic arch bleeding resulting from mediastinitis and sepsis and could not be weaned from CPB. The mean follow-up of the 34 surviving patients was 2.3 years (range 0.3 to 6.0 years). There were no reoperations for autograft failure, thromboembolic complications, or instances of endocarditis during follow-up. One patient was reoperated on 2 years after the initial operation for significant pulmonary stenosis at the distal suture line of the pulmonary allograft with secondary tricuspid regurgitation. One patient was in New York Heart Asso- ciation class II at most recent follow-up; the remaining patients were all in class I.

Diameters. Twenty-eight epicardial echocardiograms before CPB were of sufficient quality for pulmonary anulus measurement. The image quality distal to this level was poor and measurements were not reliable. Epicardial echocardiograms after CPB were available in 32 patients. Anulus measurements before and after CPB were available in 25 patients. At discharge the quality of the transthoracic echocardiogram was poor in two patients. In the remaining 32 patients, autograft anulus and sinus diameters could be measured. Transesophageal echocardiography was performed in 26 patients with a mean follow-up time of 1.9 years (range 0.3 to 5.2 years). The mean autograft anulus and sinus diameters could be measured in all patients. The mean values of all available autograft anulus and sinus measurements before and at different time points after the operation are shown in Figs. 1 and 2, respectively. The individual increase of autograft anulus and 

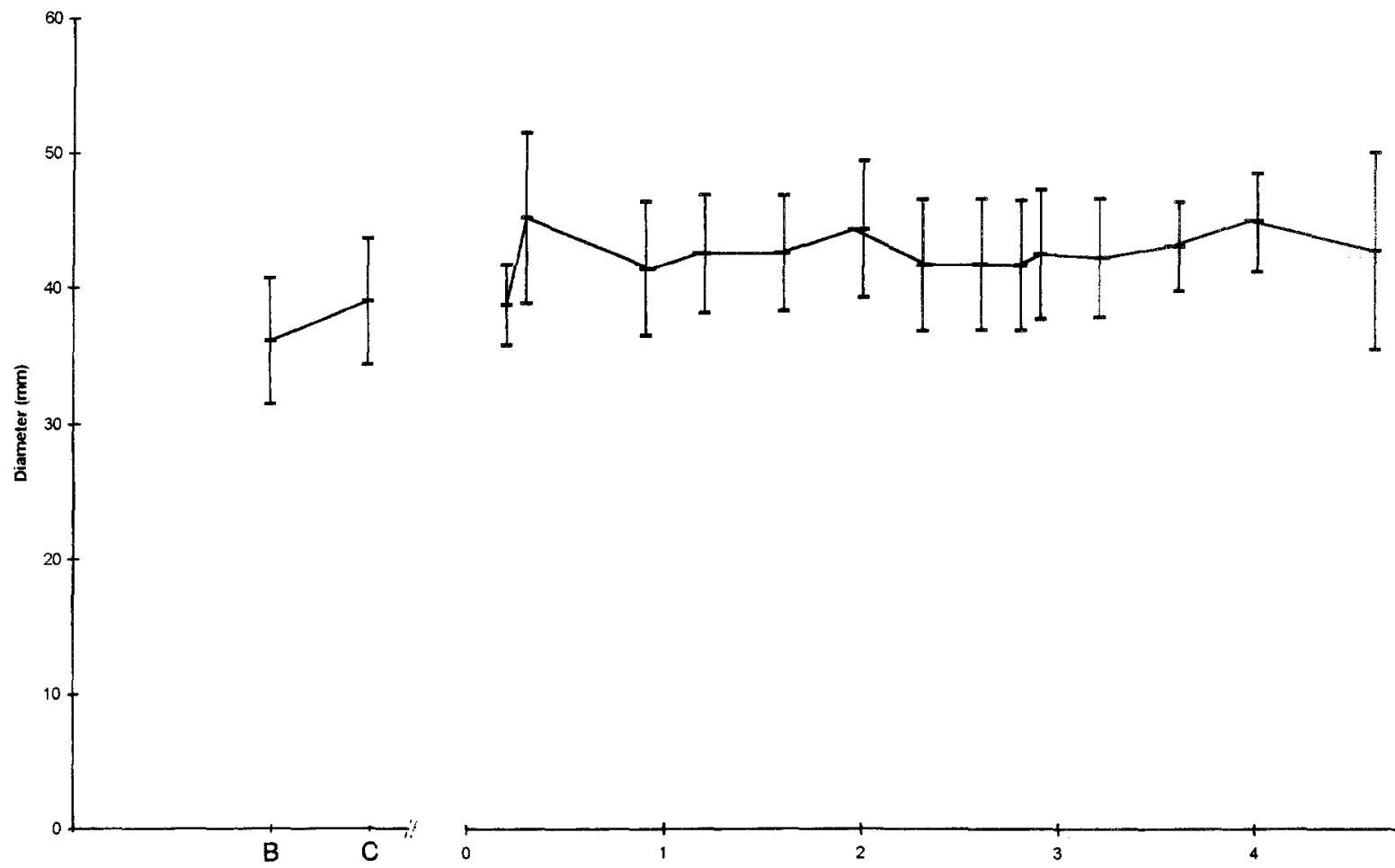

Fig. 2. Mean autograft sinus diameter, using all available measurements of 34 patients, after $C P B(B)$, at discharge $(C)$, and at follow-up. For the transesophageal echocardiographic measurements at follow-up, a "moving band" method was used. The mean sinus diameter is given with a $70 \%$ confidence interval.

sinus diameters of patients with two or more measurements available are presented in Figs. 3 and 4, respectively.

All postoperative autograft anulus measurements were available in 22 patients and all postoperative autograft sinus measurements were available in 17 patients. In these patients the diameter increase was determined (Table I). There was no statistically significant difference between the mean autograft anulus diameter before and directly after CPB (26.2 $\mathrm{mm}$ and $26.4 \mathrm{~mm}$, respectively). The mean autograft sinus diameter directly after CPB was $36.5 \mathrm{~mm}$. The mean autograft anulus and sinus diameters were larger at hospital discharge $(29.5$ and $39.6 \mathrm{~mm}$, respectively). At follow-up, the mean autograft anulus and sinus diameters were again larger when compared with the findings on the echocardiograms at discharge $(31.5 \mathrm{~mm}$ and $43.9 \mathrm{~mm}$, respectively). The repeated-measurements analysis (MANOVA) indicated that both the autograft anulus and sinus diameters increased to a statistically significant degree during follow-up ( $p<0.01$ for both analyses). A small, statistically nonsignificant increase was noted for the autograft anulus diameter before and after CPB $(p=0.6)$. Measurements thereafter were significantly larger than the initial measurements $(p<0.01$ for both analyses).

The mean increases in autograft anulus and sinus diameters at follow-up relative to the diameters after CPB were 5.1 and $7.4 \mathrm{~mm}$, respectively (see Table I). The mean relative increases were $19 \%$ and $21 \%$, respectively. A!most half of the increases in autograft anulus and sinus diameters $(59 \%$ and $40 \%$, respectively) were noted at hospital discharge; the other part occurred after discharge.

When the patients were grouped according to a follow-up time less than 1 year $(n=14)$ and more than 1 year $(n=13)$, there were no statistically significant differences with regard to absolute or relative increases of the autograft anulus and sinus diameters $(p>0.4)$.

Autograft regurgitation, measured at follow-up with transesophageal echocardiography, was absent in seven, trivial in six, and mild in 13 patients; one patient had moderate aortic regurgitation. When the patients were grouped according to the severity 


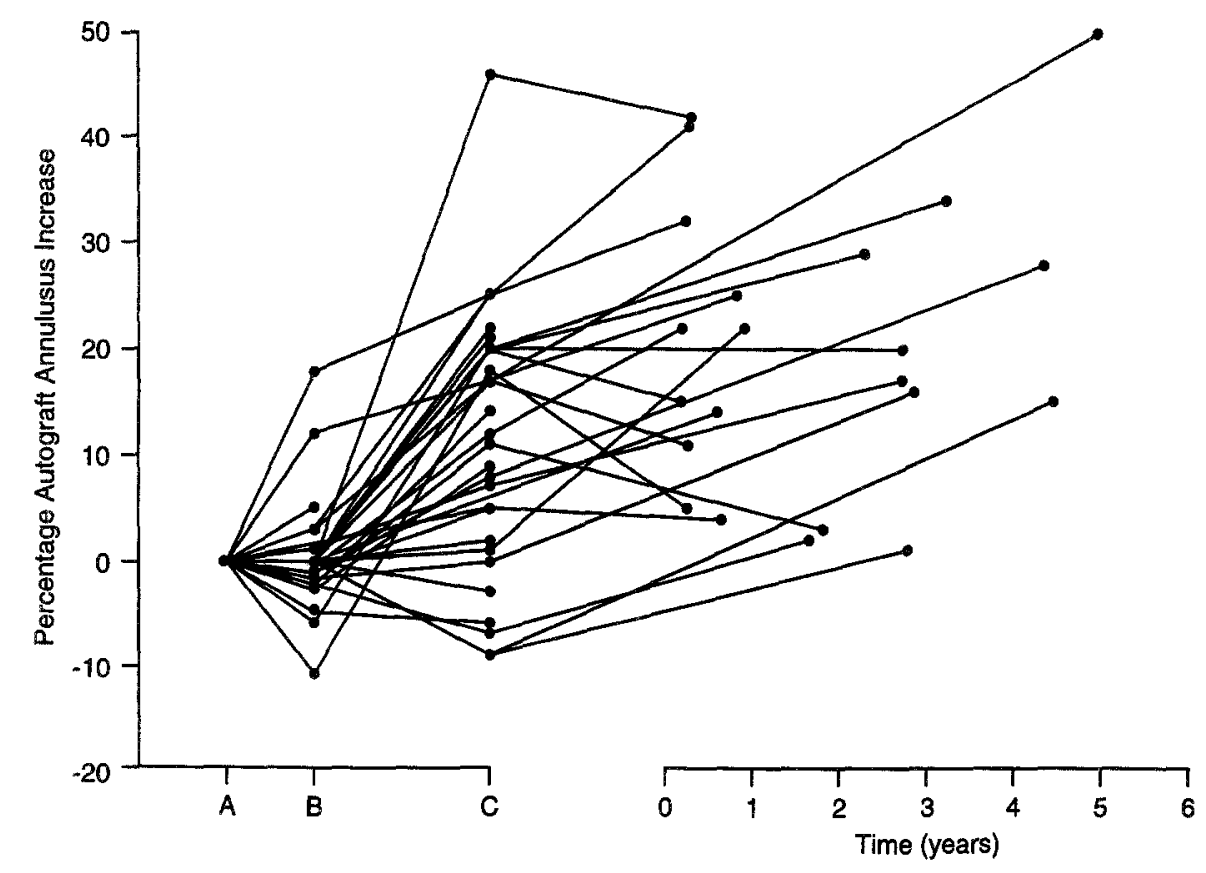

Fig. 3. The individual increase of the autograft anulus diameter of patients with two or more measurements available before $\mathrm{CPB}(A)$, after $\mathrm{CPB}(B)$, at discharge $(C)$, and at follow-up.

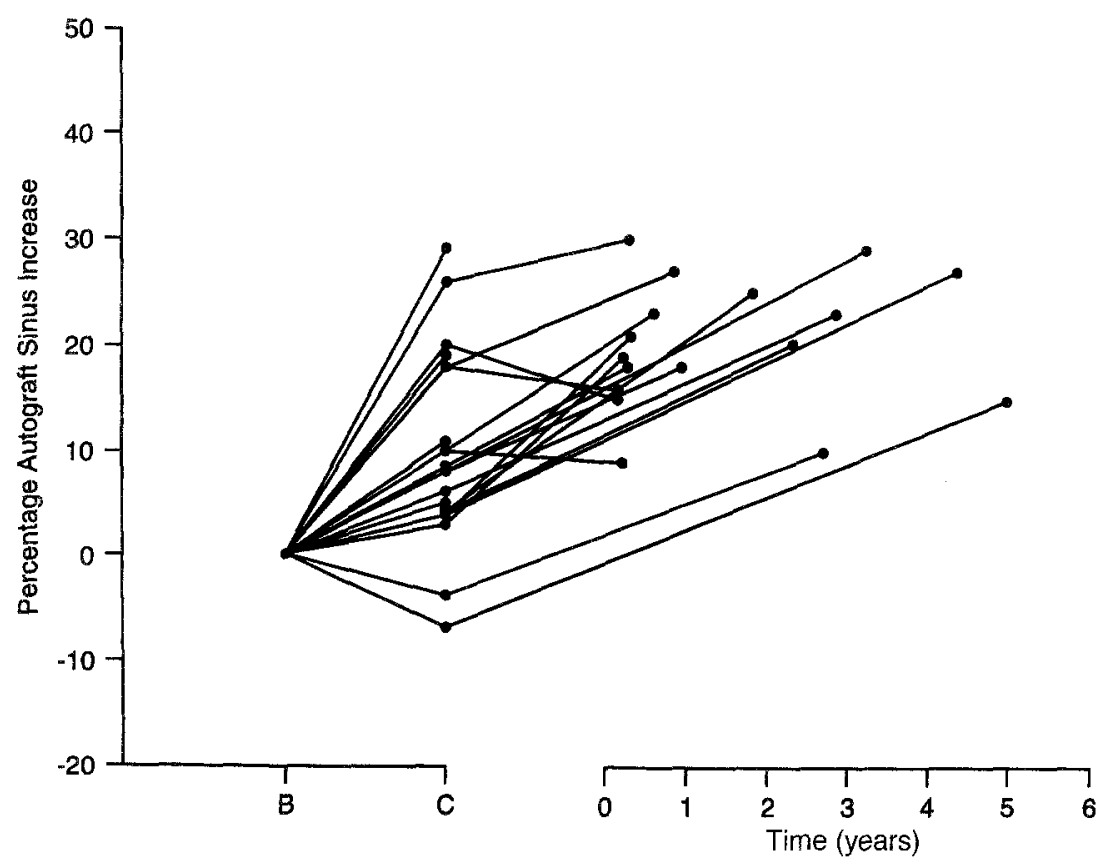

Fig. 4. The individual increase of the autograft sinus diameter of patients with two or more measurements available after $\mathrm{CPB}(B)$, at discharge $(C)$, and at follow-up.

of aortic regurgitation (none or trivial versus mild and moderate), there was no statistically significant difference with regard to absolute or relative increase of the autograft anulus and sinus diame- ters (Table II). The three patients with an increase in anulus diameter of more than $30 \%$ (see Fig. 1) had trivial $(n=2)$ and mild $(n=1)$ aortic regurgitation. 
Table I. Autograft anulus and sinus diameter measurements at different times*

\begin{tabular}{|c|c|c|c|c|}
\hline & $\begin{array}{c}\text { Anulus } \\
\text { (mm) } \\
(S D ; \text { range }) \\
\end{array}$ & $p$ Value & $\begin{array}{c}\text { Sinus } \\
(\text { mon }) \\
(S D ; \text { range }) \\
\end{array}$ & $p$ Value \\
\hline Before CPB & $\begin{array}{c}26.2 \\
(2.8 ; 21-31)\end{array}$ & $-^{\mathrm{a}}$ & - & $-{ }^{\mathrm{a}}$ \\
\hline $\begin{array}{l}\text { After CPB } \\
(\mathrm{mm})\end{array}$ & $\begin{array}{c}26.4 \\
(3.9 ; 18-34)\end{array}$ & NS & $\begin{array}{c}36.5 \\
(4.6 ; 30-46)\end{array}$ & \\
\hline $\begin{array}{l}\text { Discharge } \\
(\mathrm{mm})\end{array}$ & $\begin{array}{c}29.5 \\
(4.0 ; 24-36)\end{array}$ & $<0.001^{\mathrm{b}}$ & $\begin{array}{c}39.6 \\
(4.8 ; 26-48)\end{array}$ & $<0.001^{\mathrm{b}}$ \\
\hline $\begin{array}{l}\text { Follow-up } \\
\text { (mm) }\end{array}$ & $\begin{array}{c}31.5 \\
(4.2 ; 22-42)\end{array}$ & $<0.01^{\mathrm{c}}$ & $\begin{array}{c}43.9 \\
(5.1 ; 35-55)\end{array}$ & $<0.001^{\mathrm{c}}$ \\
\hline Increase $^{\mathrm{d}}$ & $\begin{array}{c}5.1 \\
(2.8 ; 0-10)\end{array}$ & $<0.001$ & $\begin{array}{c}7.4 \\
(2.1 ; 3-10)\end{array}$ & $<0.001$ \\
\hline$\%$ Increase & $19 \%$ & & $21 \%$ & \\
\hline
\end{tabular}

$S D$, Standard deviation; $N S$, not statistically significant.

$a, b, c, p$ Values for differences between measurements before and after $\mathrm{CPB}(a)$, between measurements after (CPB) and at discharge $(b)$, and between measurements at discharge and at follow-up $(c)$. $d$, Increase of diameter between measurements directly after CPB and at follow-up.

*Only patients with all measurements available were included. For the autograft anulus and sinus diameter measurements there were 22 and 17 patients, respectively.

Variability. With regard to the intratechnique variability, the standard deviations for autograft anulus measurements before and after CPB, at discharge, and at follow-up were 0.8, 0.6, 1.0, and 0.9 $\mathrm{mm}$, respectively. For the autograft sinus diameters after CPB, at discharge, and at follow-up, the standard deviations were $1.0,1.0$, and $0.6 \mathrm{~mm}$, respectively. The standard deviation of the measurements of the second observer for autograft anulus at discharge and at follow-up were 1.2 and $1.0 \mathrm{~mm}$, respectively. For the sinus measurements, these were 1.3 and $0.9 \mathrm{~mm}$, respectively. The difference between the first and second observer for echocardiograms at discharge and at follow-up was $0.3 \mathrm{~mm}$ (standard deviation $0.2 \mathrm{~mm}$ ) for the autograft anulus measurements and $0.2 \mathrm{~mm}$ (standard deviation $0.1 \mathrm{~mm}$ ) for the autograft sinus measurements.

\section{Discussion}

The pulmonary autograft procedure for aortic root replacement is a well-established operation technique. It seems to be a highly adequate treatment modality for children with congenital aortic valve disease. Stimulated by the good results in children, ${ }^{3,10}$ others have used the procedure in older patients, and short-term results in this age group are promising as well. ${ }^{2-4}$ This is confirmed in our series, without reoperations for autograft failure, thromboembolic complications, and endocar-
Table II. Increase in autograft anulus and sinus diameter related to semiquantitatively measured aortic regurgitation at follow-up (22 and 17 patients, respectively)

\begin{tabular}{|c|c|c|c|}
\hline & \multicolumn{2}{|c|}{ Aortic regurgitation } & \multirow[b]{2}{*}{$p$ Value } \\
\hline & None, trivial & Mild & \\
\hline Anulus (mm) & $3.3(23 \%)$ & $2.7(19 \%)$ & NS \\
\hline Sinus (mm) & $6.8(19 \%)$ & $7.8(21 \%)$ & NS \\
\hline
\end{tabular}

NS, Not statistically significant.

ditis. Moderate autograft dysfunction occurred in one patient only, and all patients were in New York Heart Association class I at their most recent follow-up examination, except for one patient in class II. Nevertheless, increasing autograft diameter remains a concern in adults with regard to the long-term results. ${ }^{2,3}$ Both the strength and durability of the pulmonary valve under systemic pressures, whether implanted in the subcoronary position or as an intraaortic cylinder, have been found adequate in the experimental as well as in the clinical situation. ${ }^{11,12}$ When the pulmonary autograft is used as a root, the thinner pulmonary wall may be subject to an increase in diameter. ${ }^{2,13-17}$ An increase in diameter has been noticed in children and is regarded as concordant with growth, although some children showed a greater increase than appropriate for body surface area $^{6,8,10}$ Studies with adult patients did not show autograft diameter increase, but diameters were studied with the first measurement being at discharge. ${ }^{2,4}$ In our study, increasing diameters of the autograft were noted. This could be expected from the work of Weerasena and associates, ${ }^{18}$ who showed dilatation of the pulmonary root (more than an aortic root) with increasing pressure and consider this a physiologic mechanism to decrease the pressure drop across the valve leaflets.

Increase of autograft anulus and sinus diameter was present between the measurements after $\mathrm{CPB}$ and at follow-up, in absolute (5.1 and $7.4 \mathrm{~mm}$, respectively) and in relative terms (19\% and $20 \%$, respectively). Fifty-nine percent of the anulus increase and $40 \%$ of the sinus increase was achieved at 7 to 10 days after the operation. This is congruent with the experiments of Kadoba and colleagues, ${ }^{19}$ who implanted a cryopreserved pulmonary allograft in the descending aorta in sheep; $60 \%$ of the dilatation occurred in the first week and the remaining $40 \%$ in the following year. 
Our observations during surgery and those of others ${ }^{4}$ show that immediately after disconnection of CPB the autograft diameter increases as the consequence of the high aortic pressures. In this study, however, we found that the diameter of the pulmonary autograft anulus did not increase immediately after CPB. This may be due to the relatively low aortic pressures (systolic 70 to $80 \mathrm{~mm} \mathrm{Hg}$ ) and to the structure of the pulmonary anulus. The observation of the increasing diameter may account for the distal part of the autograft, which has a thinner wall than the aorta. ${ }^{13,14}$

Because the increases in autograft diameters were the same for patients with a follow-up less than and more than 1 year, we conclude that the increase of autograft diameters is most prominent in the first year after the operation. Dilatation was the reason for Ross ${ }^{1}$ to stress the importance of autograft implantation within the aortic anulus, which is supported by the left ventricular musculature. For others, the possibility of dilatation was a reason to wrap the autograft root. ${ }^{15}$ Wrapping may prevent the increase in autograft diameter found in this study, but it makes the operation more complicated, necessitating longer aortic clamp times. The necessity for wrapping is mostly dependent on the relation between the increasing autograft diameter and valvular function.

Aortic regurgitation. Experimental findings and clinical experience with patients with Marfan's syndrome and idiopathic annuloaortic ectasia show a correlation between increase in aortic diameter and aortic regurgitation. ${ }^{20-22}$ Hourihan and colleagues ${ }^{23}$ reported a series of arterial switch operations for transposition of the great arteries and showed aortic regurgitation to be related to neoaortic (pulmonary artery) root diameters. In our series, with limited follow-up, no association was found between increasing autograft diameter (absolute and relative) and severity of aortic regurgitation.

Limitations to the study. The different echocardiographic techniques may account for confounding effects on the measurements. The epicardial echocardiograms were retrospectively analyzed. It was remarkable, however, that the autograft anulus measurements before and after CPB were not significantly different. Although standard deviations were acceptable with regard to intratechnique and interobserver variability, image acquisition and analyzing methods are vulnerable to imprecise calculations. We are well aware that the number of patients studied is small and the follow-up period relatively short. A longer fol- low-up period with more patients would possibly strengthen the value of our study.

\section{Conclusion}

We conclude that the autograft procedure is an attractive treatment modality for adult patients with aortic valve or root disease. The results are good with regard to hospital mortality, valve-related events, symptoms, and valve function. Autograft anulus and sinus diameters increase by $20 \%$ within the first year, especially in the first 10 days after the operation. This increase was not associated with aortic regurgitation.

We thank Ada Matser for secretarial help and Drs. Ewout W. Steyerberg and Rene Eÿkemans for statistical advice.

\section{REFERENCES}

1. Ross DN. Aortic root replacement with a pulmonary autograft: current trends. J Heart Valve Dis 1994;3:358-60.

2. Kouchoukos NT, Davila-Roman VG, Spray TL, Morphy SF, Perillo JB. Replacement of the aortic root with a pulmonary autograft in children and young adults with aortic valve disease. N Engl J Med 1994;330:1-6.

3. Hokken RB, Bogers AJJC, Taams MA, et al. Aortic root replacement with a pulmonary autograft. Eur $\mathbf{J}$ Cardiothorac Surg 1995;9:378-83.

4. Sievers HH, Leyh R, Loose R, Guha M, Petry A, Bernhard A. Time course of dimension and function of the autologous pulmonary root in the aortic position. J Thorac Cardiovasc Surg 1993;105:775-80.

5. Oury JH, Eddy AC, Cleveland JC. The Ross procedure: a progress report. J Heart Valve Dis 1994;3:361-4.

6. Gerosa G, McKay R, Ross DN. Replacement of the aortic valve or root with a pulmonary autograft in children. Ann Thorac Surg 1991;51:424-9.

7. Elkins RC, Santangelo K, Randolph JD, et al. Pulmonary autograft replacement in children: The ideal solution? Ann Surg 1992;216:363-71.

8. Schoof PH, Cromme-Dijkhuis AH, Bogers AJJC, et al. Aortic root replacement with pulmonary autograft in children. J Thorac Cardiovasc Surg 1994;107:367-73.

9. Kendall MG. Moving averages. In: Kendall MG, editor. Time series. London: Giffin, 1973:47-54.

10. Elkins RC, Knott-Craig CJ, Ward KE, McCue C, Lane MM. Pulmonary autograft in children: realized growth potential. Ann Thorac Surg 1994;57:1387-94.

11. Gorczynski A, Trenkner M, Anisimowicz L, et al. Biomechanics of the pulmonary autograft valve in the aortic position. Thorax 1982;37:535-9.

12. Matsuki O, Okita Y, Almeida RS, McGoldrick JP, et al. Two decades' experience with aortic valve replacement with pulmonary autograft. J Thorac Cardiovasc Surg 1988;95:705-11.

13. Plank L, James J, Wagenvoort CA. Caliber and elastin content of the pulmonary trunk. Arch Pathol Lab Med 1980;104:238-41.

14. Heath D, Wood EH, DuShane JW, et al. The structure of the pulmonary trunk at different ages and in cases of pulmonary 
hypertension and pulmonary stenosis. J Pathol Bacteriol 1959;77:443-56.

15. Pacifico AD, Kirklin JK, McGiffin DC, Matter GJ, Nanda NC, Diethelm AG. The Ross operation: early echocardiographic comparison of different operative techniques. J Heart Valve Dis 1994;3:365-70.

16. Angell WW, Pupello DF, Bessone LN, Him SP, LopezCuenca E, Glatterer MS. Partial inclusion aortic root replacement with the pulmonary autograft valve. J Heart Valve Dis 1993;2:388-94.

17. Daenen W, Gewillig M. Extended aortic root replacement with pulmonary autografts. Eur J Cardiothorac Surg 1993;7:42-6.

18. Weerasena N, Lockie KJ, Butterfield M, Fisher J, Kearney JN, Davies GA. The hydrodynamic function and leaflet dynamics of aortic and pulmonary root and valves: an in vitro study. Eur J Cardiothorac Surg 1992;6:350-6.
19. Kadoba K, Armiger LC, Sawatari K, Jonas RA. Mechanical durability of pulmonary allograft conduits at systemic pressure: angiographic and histologic study in lambs. J Thorac Cardiovasc Surg 1993;105:132-41.

20. Bellhouse BJ, Bellhouse F, Abbott JA, Talbot L. Mechanism of valvular incompetence in aortic sinus dilatation. Cardiovasc Res 1973;7:490-4.

21. Pyeritz RE. The Marfan syndrome: Am Fam Phys 1986;34: 83-94.

22. Roman MJ, Devereux RB, Niles NW, et al. Aortic root dilatation as a cause of isolated, severe aortic regurgitation. Ann Intern Med 1987;106:800-7.

23. Hourihan M, Colan SD, Wernovski G, Maheswari U, Mayer JE, Sanders SP. Growth of the aortic anastomosis, annulus, and root after the arterial switch procedure performed in infancy. Circulation 1993;88:615-20.

\section{Bound volumes available to subscribers}

Bound volumes of The Journal of Thoracic and Cardiovascular Surgery are available to subscribers (only) for the 1997 issues from the Publisher, at a cost of $\$ 110.50$ for domestic, $\$ 139.64$ for Canadian, and $\$ 130.50$ for international subscribers for Vol. 113 (January-June) and Vol. 114 (July-December). Shipping charges are included. Each bound volume contains a subject and author index and all advertising is removed. Copies are shipped within 60 days after publication of the last issue of the volume. The binding is durable buckram with the Journal name, volume number, and year stamped in gold on the spine. Payment must accompany all orders. Contact Mosby-Year Book, Inc., Subscription Services, 11830 Westline Industrial Drive, St. Louis, Missouri 63146-3318, USA; phone $800-453-4351$ or 314-453-4351.

Subscriptions must be in force to qualify. Bound volumes are not available in place of a regular Journal subscription. 